\title{
Biologics Prescribing for Rheumatoid Arthritis in Older Patients: A Single-Center Retrospective Cross-Sectional Study
}

\author{
Klara Morsley $\cdot$ Thomas Kilner $\cdot$ Alan Steuer
}

Received: October 3, 2015 / Published online: November 25, 2015

(C) The Author(s) 2015. This article is published with open access at Springerlink.com

\begin{abstract}
Introduction: Appropriate medical treatment can reduce the morbidity and mortality associated with rheumatoid arthritis (RA). Studies have shown that older patients with RA may be treated less aggressively than their younger counterparts, despite evidence suggesting that biologic treatments may be safe and efficacious in older age groups. The aim of this study was to assess whether patient age was associated with biologic treatment for RA in a single center in the United Kingdom.
\end{abstract} Methods: This was a retrospective cross-sectional analysis of clinic records for all patients with RA reviewed over 1 year in our center. Data were also collected on healthcare

Electronic supplementary material The online version of this article (doi:10.1007/s40744-015-0021-z) contains supplementary material, which is available to authorized users.

K. Morsley ( $\square)$

Royal Berkshire Hospital, Reading, UK

e-mail: klara.m@doctors.org.uk

T. Kilner

Newham University Hospital, London, UK

A. Steuer

Wexham Park Hospital, Slough, UK use in patients aged 65 years and older as a surrogate marker of comorbidity.

Results: In total, 856 patients with RA were identified, of which $22.8 \%$ were on biologic treatment. Patients on biologics were younger (mean age 58.9 years) compared to the mean age of all patients (61.4 years). Of patients aged less than 65 years, $27.2 \%$ were receiving biologic treatment, while only $15.2 \%$ of patients aged 65 years or older were on biologics. Increasing age was significantly associated with a lower likelihood of receiving biologic treatment. However, in patients 65 years or older, there was no significant difference in overall healthcare use between those on biologic treatment and those not. Patients treated with prednisolone were found to have a greater number of admissions.

Conclusion: In our center, older patients are less likely to receive biologic treatment than younger patients. Among older patients we found no difference in healthcare use between those treated with biologics and those not, suggesting similar levels of comorbidity. Potential contributors are discussed, but further assessment is required to determine the reasons for this observation. 
Keywords: Aging; Rheumatoid arthritis; Biological therapy

\section{INTRODUCTION}

Rheumatoid arthritis (RA) is a chronic systemic inflammatory disorder that predominantly involves joints, but may affect almost any part of the body. The prevalence of RA in the United Kingdom has been estimated at $0.81 \%$, but is higher in older patients, up to $2.99 \%$ in females over 75 years [1]. RA leads to increased mortality [2] and progressive disability [3]. This has considerable socioeconomic cost, in terms of loss of work productivity, reduced life activities and in healthcare resource use [4].

Treatment options for RA have increased dramatically over recent years with the development of biologic treatments. This group of treatments includes tumor necrosis factor-alpha inhibitors (TNFi, including etanercept, adalimumab, infliximab, golimumab, and certolizumab), anti-interleukin six agents (tocilizumab), B cell depleting agents (rituximab), and CTLA4 therapy (abatacept). Evidence suggests that use of biologic treatment leads to rapid attainment of remission, slows radiological progression [5], and reduces disability [6]. Additionally, biologics have been shown to improve work participation [7] and quality of life [8].

Several studies on biologic treatment in older patients have shown no increase in the risk of serious infections compared to non-biologic treatments $[9,10]$, or compared to biologic use in younger patients [11-13]. Similar efficacy has also been demonstrated in older and younger patients [14-16]. However, prescribing practice does not appear to reflect this, with older patients likely to receive less aggressive treatment [17-23].
This study aims to: (1) assess the pattern of biologic prescribing at our center; (2) assess the pattern of healthcare resource use associated with RA treatment in older patients at our center, and (3) determine whether age is independently associated with the use of biologic treatments for RA at our center.

\section{METHODS}

A retrospective cross-sectional analysis of clinic records of all patients with a recorded diagnosis of RA seen in one outpatient department over a 12-month period (January 1, 2014 to December $31,2014)$ was undertaken by the lead author. All patients with a documented diagnosis of RA on their clinic letter who were seen in outpatients within this period were included. Age, gender, and RA treatment were obtained from the clinic letters. Age was defined as the patient's age on January 1, 2014. When a patient was seen in clinic more than once in a year, the treatment stated on the latest clinic letter was recorded. Within the department, the decision to use biologic treatment is made in accordance with the National Institute for Health and Care Excellence guidelines [24]. For patients aged 65 years or older, data on outpatient clinic attendances, emergency department (ED) attendances, and hospital admissions during the study period were collected from the hospital's electronic records system. This data was used as a surrogate marker of the patient's level of comorbidity.

The $t$ test was used to compare mean ages, and the mean healthcare use of different treatment groups. The $z$ test was used to compare the proportions of different treatment groups utilizing healthcare resources. Multivariable logistic regression models were constructed [25] to determine 
whether age was associated with prednisolone, or biologic treatment. Each of the two multivariable models contained the a priori input variables: age, gender, number of admissions, ED attendances, number of orthopedic clinic attendances, number of rheumatology clinic attendances, and number of other specialty clinic attendances. No evidence of variable multicollinearity or model specification error was found. Analysis was performed using Stata Statistical Software (Release 11; StatCorp LP, College Station, TX, USA).

All procedures performed in studies involving human participants were in accordance with the ethical standards of the institutional and/or national research committee and with the 1964 Helsinki declaration and its later amendments or comparable ethical standards. For this type of study formal consent is not required.

\section{RESULTS}

\section{Pattern of Biologic Prescribing}

Out of all National Health Service patients seen in the rheumatology clinic at our secondary care hospital, 856 patients with a diagnosis of RA were identified. Of these, 189 were on biologic treatment $(22.8 \%)$. The mean age of all patients with RA was 61.4 years (range 21.3-92.2 years), whilst the mean age of patients on biologics was 58.9 years (range 21.8-90.9 years).

Of the 493 patients aged less than 65 years, 134 were on biologics (27.2\%). In those aged 65 years or older, 55 of 366 patients received biologic treatment (15.0\%).

Etanercept was the most commonly used biologic, followed by rituximab and adalimumab. Patients aged 65 years or older on biologic treatment were more likely to receive rituximab than patients less than 65 years of age on biologic treatment $(32.7 \%$ vs. $25.4 \%$, respectively). These results are shown in Table 1.

Out of the 366 patients aged 65 years or older, 55 patients (average age 72.3 years) were on biologics treatment, 280 (average age 71.5 years) on disease-modifying anti-rheumatic drugs (DMARDs, including azathioprine, ciclosporin, gold, hydroxychloroquine, leflunomide, methotrexate, mycophenolate, penicillamine, sulfasalazine), 60 (average age 76.2 years) on long-term prednisolone, and 39 patients (average age 77.0 years) were on no treatment.

Table 1 Number of patients on biologic treatment

\begin{tabular}{lccc}
\hline Biologics & \multicolumn{2}{c}{ Age group } & \multicolumn{1}{c}{ All $^{\mathbf{c}}$} \\
\cline { 2 - 3 } & $\mathbf{2 6 5}$ years $^{\mathbf{a}}$ & $<\mathbf{6 5}$ years & \\
\hline All biologics & $55(15.03)$ & $134(27.18)$ & $189(22.08)$ \\
ETA & $17(30.91)$ & $46(34.33)$ & $63(33.33)$ \\
ADA & $13(23.64)$ & $32(23.88)$ & $45(23.81)$ \\
CER & $4(7.27)$ & $12(8.96)$ & $16(8.47)$ \\
INF & $2(3.64)$ & $1(0.75)$ & $3(1.59)$ \\
GOL & $0(0.00)$ & $2(1.49)$ & $2(1.06)$ \\
TOC & $1(1.82)$ & $7(5.22)$ & $8(4.23)$ \\
ABA & $0(0.00)$ & $0(0.00)$ & $0(0.00)$ \\
RIT & $18(32.73)$ & $34(25.37)$ & $52(27.51)$ \\
\hline ANl & & &
\end{tabular}

All values given are $n(\%)$

$A B A$ abatacept, $A D A$ adalimumab, $C E R$ certolizumab, $E T A$ etanercept, $G O L$ golimumab, INF infliximab, RIT rituximab, $T O C$ tocilizumab

a $N=366$; average age $=75.1$ years

b $N=493$; average age $=51.2$ years

c $N=859$; average age $=61.4$ years 


\section{Healthcare Resource Use in Older Patients}

We observed considerable resource use by patients with RA aged 65 years or more, with over 2000 outpatient appointments being used for this group of 366 patients, and over 100 admissions in the course of 1 year.

Among patients aged 65 years or older, those on biologic treatment were not significantly different from those not on biologic treatment in terms of gender, average number of admissions per patient per year, proportion of patients admitted at least once, average number of ED attendances per year, proportion of patients attending ED at least once, or number of non-rheumatology appointments per patient per year. They attended fewer orthopedic outpatient appointments. These results are shown in Table 2.

In patients aged 65 years or older, patients on prednisolone treatment were not significantly different in terms of gender or age from those not receiving prednisolone treatment. However, they were significantly more likely to attend ED, be admitted and attend non-rheumatology outpatient appointments. These results are shown in Table 3.

\section{Association Between Age and Biologic Treatment in Patients Aged 65 Years or Older}

There was strong evidence of an association between increasing age and not being treated with a biologic following adjustment for gender, number of admissions, ED attendances, number of orthopedic clinic attendances, number of rheumatology clinic attendances, and number of other specialty clinic attendances. After adjusting for all other variables, an association was also found between the number of orthopedic clinic attendances and receiving biologic treatment, and between the number of rheumatology appointments and receiving biologic treatment (Table 4).

After adjusting for gender, number of admissions, ED attendances, number of orthopedic clinic attendances, number of rheumatology clinic attendances, and number of other specialty clinic attendances, there was no evidence of an association between age and being

Table 2 Comparison of patients with rheumatoid arthritis aged $\geq 65$ years on biologic treatment with those not on biologic treatment

\begin{tabular}{llll}
\hline Characteristics & On biologics & Not on biologics & $P$ value \\
\hline Female (\%) & 76.4 & 70.7 & 0.395 \\
Average age (years) & 72.25 & 75.55 & 0.0001 \\
\% of pts with $\geq 1$ admission & 20 & 19.29 & 0.904 \\
Admissions per pt per year & 0.27 & 0.29 & 0.829 \\
\% of all pts with $\geq 1$ ED attendance & 21.82 & 23.15 & 0.826 \\
ED attendances per pt per year & 0.33 & 0.41 & 0.471 \\
Non-rheumatology appointments per pt per year & 3.04 & 3.2 & 0.789 \\
\% of all pts attending $\geq 1$ orthopedic appointment & 16.36 & 19.94 & 0.535 \\
Orthopedic appointments per pt per year & 1.89 & 3.21 & 0.024 \\
\hline
\end{tabular}

$E D$ emergency department, $p t$ patient 
Table 3 Comparison of patients with rheumatoid arthritis aged $\geq 65$ years on prednisolone treatment with those not on prednisolone treatment

\begin{tabular}{llll}
\hline Characteristics & On prednisolone & Not on prednisolone & $\boldsymbol{P}$ value \\
\hline Female (\%) & 78.3 & 70.3 & 0.204 \\
Average age (years) & 76.2 & 74.8 & 0.125 \\
\% of pts with $\geq 1$ admission (\%) & 33.33 & 16.67 & 0.003 \\
Admissions per pt per year & 0.73 & 0.20 & 0.008 \\
\% of all pts with $\geq 1$ ED attendance (\%) & 38.33 & 19.93 & 0.002 \\
ED attendances per pt per year & 0.87 & 0.30 & 0.009 \\
Non-rheumatology appointments per pt per year & 4.63 & 2.89 & 0.013 \\
\% of all pts attending $\geq 1$ orthopedic appointment & 20 & 19.28 & 0.896 \\
Orthopedic appointments per pt per year & 3.08 & 3.03 & 0.891 \\
\hline
\end{tabular}

$E D$ emergency department, $p t$ patient

Table 4 Adjusted ORs for receiving biologic treatment in patients aged $\geq 65$ years

\begin{tabular}{llr}
\hline Variable & OR $(\mathbf{9 5 \%}$ CI $)$ & $\boldsymbol{P}_{\text {value }}^{\mathbf{a}}$ \\
\hline Age & $0.94(0.89-0.99)$ & 0.022 \\
Gender & $1.16(0.55-2.48)$ & 0.692 \\
ED attendance & $0.99(0.55-1.78)$ & 0.974 \\
Hospital admission & $1.07(0.53-2.17)$ & 0.842 \\
Orthopedic clinic attendance & $0.74(0.53-1.03)$ & 0.032 \\
Rheumatology clinic attendance & $1.98(1.59-2.47)$ & $<0.001$ \\
All other clinic attendance & $1.99(0.90-1.11)$ & 0.983 \\
\hline
\end{tabular}

$C I$ confidence interval, $E D$ emergency department, $O R$ odds ratio

${ }^{\text {a }}$ Likelihood ratio test

treated with prednisolone. However, after adjusting for all other variables an association was found, between the number of admissions and being treated with prednisolone, and between the number of rheumatology appointments and being treated with prednisolone (Table 5).

\section{DISCUSSION}

Despite many studies showing that biologics are safe and effective in older patients, we have demonstrated that in our center, younger patients are more likely than older patients to be prescribed biologic treatment. We also found that resource use was high in those patients over 65 years of age. For the most part, this did not differ considerably between those on biologics and those not on biologics, suggesting that comorbidity in both groups may have been similar. However, our study did not consider the presence of comorbidities directly, which may have been more important than age in the decision to prescribe or withhold treatment. For instance, one study 
Table 5 Adjusted ORs for receiving prednisolone in patients aged $\geq 65$ years

\begin{tabular}{llr}
\hline Variable & OR $(\mathbf{9 5 \%}$ CI) & $\boldsymbol{P}_{\text {value }^{\mathbf{a}}}$ \\
\hline Age & $1.05(1.00-1.10)$ & 0.070 \\
Gender & $1.73(0.85-3.53)$ & 0.121 \\
ED attendance & $1.12(0.78-1.61)$ & 0.555 \\
Hospital admission & $1.72(1.02-2.89)$ & 0.032 \\
Orthopedic clinic attendance & $0.99(0.82-1.20)$ & 0.928 \\
Rheumatology clinic attendance & $1.38(1.17-1.63)$ & $<0.001$ \\
All other clinic attendance & $1.06(0.97-1.15)$ & 0.220 \\
\hline
\end{tabular}

$C I$ confidence interval, $E D$ emergency department, $O R$ odds ratio

${ }^{\mathrm{a}}$ Likelihood ratio test

found that the presence of diabetes and respiratory conditions increased the risk of infection and pneumonia in older patients with RA treated with biologics [26].

Many of our patients aged 65 years or over were treated with prednisolone, a treatment with well recognized limitations [27]. In our center, in the over 65 years age group, there was no association between increasing age and being prescribed prednisolone, but these patients had higher levels of comorbidity, as measured by more ED attendances, hospital admissions, and outpatient appointments. There are three likely contributing factors for this increased healthcare use; firstly, higher healthcare needs related to steroid side effects, for example increased fracture risk; secondly, these patients may have poorer disease control and so accumulate more damage; and thirdly, patients with a poorer health status are more likely to be given prednisolone rather than intensive DMARD/biologic treatment.

There are several potential limitations to our study. Firstly, data on disease activity and duration of disease were not available for analysis; it has been assumed that disease activity is similar in younger and older patients, whereas, it is possible that older patients may have less active inflammatory disease. Secondly, comorbidities were not able to be directly analyzed in our study; since comorbidities often vary with age, they may have had a potential confounding effect on our findings. Thirdly, this study did not consider clinicians' interpretation of the literature, which may have influenced their prescribing practice, as not all studies agree that biologics are as safe and efficacious in older patients, particularly with biologics that are not TNFi [28-31]. Finally, as only treatment at one point in the study period was recorded, it is possible that the proportion of patients stopping treatment during the study period was different in older and younger patients, limiting the interpretation of our results.

\section{CONCLUSIONS}

We observed a significant association between older age and not being prescribed biologics, whereas no association was found between older age and being prescribed prednisolone. The reasons for this were unclear, though patient factors such as number and type of comorbidities, preference and adherence, and clinician factors such as training and 
experience, and attitude towards risk-taking could have been contributory. Further studies are needed to explore the rationale for clinicians' biologic prescribing patterns in older patients.

\section{ACKNOWLEDGMENTS}

No funding or sponsorship was received for this study or publication of this article. All named authors meet the International Committee of Medical Journal Editors (ICMJE) criteria for authorship for this manuscript, take responsibility for the integrity of the work as a whole, and have given final approval for the version to be published.

Disclosures. Klara Morsley, Thomas Kilner, and Alan Steuer declare that they have no conflict of interest.

Compliance with Ethics Guidelines. All procedures performed in studies involving human participants were in accordance with the ethical standards of the institutional and/or national research committee and with the 1964 Helsinki declaration and its later amendments or comparable ethical standards. For this type of study formal consent is not required.

Open Access. This article is distributed under the terms of the Creative Commons Attribution-NonCommercial 4.0 International License (http://creativecommons.org/licenses/ by-nc/4.0/), which permits any noncommercial use, distribution, and reproduction in any medium, provided you give appropriate credit to the original author(s) and the source, provide a link to the Creative Commons license, and indicate if changes were made.

\section{REFERENCES}

1. Symmons D, Turner G, Webb R. The prevalence of rheumatoid arthritis in the United Kingdom: new estimates for a new century. Rheumatol Oxf Engl. 2002;41:793-800.

2. Sokka T, Abelson B, Pincus T. Mortality in rheumatoid arthritis: 2008 update. Clin Exp Rheumatol. 2008;26:35-61.

3. Kapetanovic M, Lindqvist E, Nilsson J-A. Development of functional impairment and disability in rheumatoid arthritis patients followed for 20 years: relation to disease activity, joint damage, and comorbidity. Arthritis Care Res. 2015;67:340-8.

4. Boonen A, Severens J. The burden of illness of rheumatoid arthritis. Clin Rheumatol. 2011;30:3-8.

5. Ornbjerg L, Ostergaard M, Boyesen P. Impact of tumour necrosis factor inhibitor treatment on radiographic progression in rheumatoid arthritis patients in clinical practice: results from the nationwide Danish DANBIO registry. Ann Rheum Dis. 2013;72:57-63.

6. Hallert E, Husberg M, Bernfort L. The incidence of permanent work disability in patients with rheumatoid arthritis in Sweden 1990-2010: before and after introduction of biologic agents. Rheumatol Oxf Engl. 2012;51:338-46.

7. Ter Wee M, Lems $W$, Usan $H$. The effect of biological agents on work participation in rheumatoid arthritis patients: a systematic review. Ann Rheum Dis. 2012;71:161-71.

8. Chen J, Makovey J, Lassere M. Comparative effectiveness of anti-tumor necrosis factor drugs on health-related quality of life among patients with inflammatory arthritis. Arthritis Care Res. 2014;66:464-72.

9. Schneeweiss S, Setoguchi S, Weinblatt M. Anti-tumor necrosis factor $\alpha$ therapy and the risk of serious bacterial infections in elderly patients with rheumatoid arthritis. Arthritis Rheumatol. 2007;56:1754-64.

10. Fleischmann R, Baumgartner SW, Weisman MH. Long term safety of etanercept in elderly subjects with rheumatic diseases. Ann Rheum Dis. 2006;65:379-84.

11. Fleischmann R, Baumgartner S, Tindall E. Response to etanercept (Enbrel) in elderly patients with rheumatoid arthritis: a retrospective analysis of 
clinical trial results. J Rheumatol Suppl. 2003;30:691-6.

12. Radovits B, Kievit W, Laan R. Tumour necrosis factor-alpha antagonists in the management of rheumatoid arthritis in the elderly: a review of their efficacy and safety. Drugs Ageing. 2009;26:647-64.

13. Galloway J, Hyrich K, Mercer L. Anti-TNF therapy is associated with an increased risk of serious infections in patients with rheumatoid arthritis especially in the first 6 months of treatment: updated results from the British Society for Rheumatology Biologics Register with special emphasis on risks in the elderly. Rheumatol Oxf Engl. 2011;50:124-31.

14. Bathon J, Fleischmann R, van der Heijde D. Safety and efficacy of etanercept treatment in elderly subjects with rheumatoid arthritis. J Rheumatol. 2006;33:234-43.

15. Genevay S, Finckh A, Ciurea A. Tolerance and effectiveness of anti-tumor necrosis factor $\alpha$ therapies in elderly patients with rheumatoid arthritis: a population-based cohort study. Arthritis Care Res. 2007;57:679-85.

16. Schiff M, Yu E, Weinblatt M. Long-term experience with etanercept in the treatment of rheumatoid arthritis in elderly and younger patients. Drugs Ageing. 2006;23:167-78.

17. Lacaille D, Anis A, Guh D. Gaps in care for rheumatoid arthritis: a population study. Arthritis Care Res. 2005;53:241-8.

18. Tutuncu Z, Reed G, Kremer J. Do patients with older-onset rheumatoid arthritis receive less aggressive treatment? Ann Rheum Dis. 2006;65:1226-9.

19. Innala L, Berglin E, Moller B. Age at onset determines severity and choice of treatment in early rheumatoid arthritis: a prospective study. Arthritis Res Ther. 2014;16:94.

20. Yelin E, Tonner C, Kim S. Sociodemographic, disease, health system, and contextual factors affecting the initiation of biologic agents in rheumatoid arthritis: a longitudinal study. Arthritis Care Res. 2014;66:980-9.

21. Harrald L, Peterson D, Beard A. Time trends in medication use and expenditures in older rheumatoid arthritis patients. Am J Med. 2012;125:937.

22. Ng B, Chu A, Khan M. A retrospective cohort study: 10-year trend of disease-modifying antirheumatic drugs and biological agents use in patients with rheumatoid arthritis at Veteran Affairs Medical Centers. Rheumatol Oxf Engl. 2012;3(4):e002468.

23. Radovits B, Fransen J, Eijsbouts A. Missed opportunities in the treatment of elderly patients with rheumatoid arthritis. Rheumatol Oxf Engl. 2009;48:906-10.

24. Rheumatoid arthritis: the management of rheumatoid arthritis in adults [Internet]. National Institute of Health and Care Excellence; 2009. Available from: http://www.nice.org.uk/guidance/ cg79/chapter/introduction. Accessed Sept 3, 2015.

25. Stata Statistical Software. Release 11. College Station: StataCorp LP; 2009.

26. Iwanaga $\mathrm{N}$, Arima $\mathrm{K}$, Terada K. Risk factors of adverse events during treatment in elderly patients with rheumatoid arthritis: an observational study. Int J Rheum Dis. 2014. doi:10.1111/1756-185X. 12348.

27. Moreland L, O'Dell J. Glucocorticoids and rheumatoid arthritis: back to the future? Arthritis Rheum. 2002;46:2553-63.

28. Pers Y-M, Schaub R, Constant E. Efficacy and safety of tocilizumab in elderly patients with rheumatoid arthritis. Joint Bone Spine. 2015;82:25-30.

29. Payet S, Soubrier M, Perrodeau E. Efficacy and safety of rituximab in elderly patients with rheumatoid arthritis enrolled in a French Society of Rheumatology Registry. Arthritis Care Res. 2014;66:1289-95.

30. Salmon JH, Gottenberg JE, Ravaud P. Predictive risk factors of serious infections in patients with rheumatoid arthritis treated with abatacept in common practice: results from the Orencia and Rheumatoid Arthritis (ORA) registry. Ann Rheum Dis. doi:10.1136/annrheumdis-2015-207362.

31. Flouri I, Markatseli T, Voulgari P. Comparative effectiveness and survival of infliximab, adalimumab, and etanercept for rheumatoid arthritis patients in the Hellenic Registry of Biologics: low rates of remission and 5-year drug survival. Semin Arthritis Rheum. 2014;43:447-57. 